\title{
Redação do relato de caso
}

\author{
Writing a case report
}

\section{Winston Bonetti Yoshida*}

O relato de caso é um dos tipos mais comuns de apresentação em congressos ou publicação em revistas. Embora não seja considerado uma fonte científica de alto nível de evidência (nível VII) ${ }^{1}$, é uma importante fonte de informação que, em geral, permanece esquecida ou excluída dos grandes estudos multicêntricos ${ }^{2}$, e que pode fornecer subsídios fundamentais para o melhor tratamento dos pacientes em determinadas situações. Por exemplo, a primeira publicação sobre a associação de sarcoma de Kaposi e AIDS foi feita através de um relato de caso ${ }^{3}$. O mesmo ocorreu com o primeiro relato de implante de endoprótese para tratamento de aneurisma de aorta abdominal ${ }^{4,5}$.

De acordo com as normas da maioria das revistas, inclusive esta, a comunicação de um caso é pertinente quando a entidade diagnosticada é rara, o tratamento é pioneiro ou tem alguma inovação, ou o resultado é inusitado. Do ponto de vista ético, de acordo com algumas Comissões de Ética, aparentemente não há necessidade de aprovação prévia para relato de casos, mas havendo a oportunidade, recomenda-se obter o consentimento do paciente. Conflitos de interesse devem ser declarados.

Para que o relato de caso cumpra este papel informativo importante, é preciso que tenha conteúdo e seqüência apropriados. A estrutura básica do relato de caso inclui título, resumo, uma introdução com objetivo, a descrição do caso, técnica ou situação, uma discussão com revisão da literatura, conclusão e biblio-

* Editor-chefe, J Vasc Bras.

J Vasc Bras 2007;6(2):112-113.

Copyright $\odot 2007$ by Sociedade Brasileira de Angiologia e de Cirurgia Vascular grafia. Adicionalmente, figuras, tabelas, gráficos e ilustrações complementam este tipo de publicação. No total, o manuscrito deve ter cerca de 1.500 a 2.500 palavras e no máximo 20 ou 30 referências. Como toda publicação, o texto deve ser simples, claro, preciso e conciso $^{6}$.

O título deve ser sucinto, descritivo e acurado ${ }^{2}$. O resumo deve conter entre 150 e 200 palavras, e contemplar todos os itens descritos no texto. Dependendo da revista, deverá ou não ser estruturado. A introdução deve ser igualmente concisa e conter informação disponível sobre o assunto, o contexto, o mérito e o objetivo do relato, de modo a atrair a atenção do leitor. É recomendável que se faça uma revisão extensa da literatura sobre o assunto, mas não é obrigatório que o artigo contemple tudo o que foi levantado, apenas o que for mais relevante e abrangente ${ }^{7}$. Se o número de citações encontradas for pequeno, pode-se colocá-las em ordem cronológica ou, se forem em grande número, pode-se agrupá-las por algum critério ${ }^{6}$. A estratégia de busca das referências e bases de dados consultadas deve ser informada. Normalmente, deve-se incluir nesta pesquisa pelo menos as bases do MEDLINE, EMBASE, LILACS e SciELO. Referências de artigos de revisão, de revisões sistemáticas e de metanálises devem igualmente ser exploradas para uma revisão abrangente.

Na descrição do caso, a seqüência deve ser cronológica, organizada, com detalhes suficientes para que o leitor estabeleça sua interpretação, eliminando dados supérfluos, detalhes de datas dos exames, dados confusos ou não confirmados. Em se tratando de vários casos, estes devem ser sequencialmente relatados. Qualquer 
indicação para a identificação do paciente deve ser suprimida. O relato deve conter dados demográficos (idade, peso, sexo, cor, ocupação), história clínica, exame físico e exames complementares alterados, em frases e parágrafos concatenados e completos, sem informações truncadas ou soltas. Deve-se evitar incluir evolução diária, interconsultas e exames rotineiros normais. $\mathrm{O}$ autor deve estabelecer uma relação temporal e causal com a situação relatada. As datas de referência ou de ocorrência de eventos devem ser relativas à internação ou intervenção principal, evitando-se colocar como referência a data de nascimento ou data real do atendimento (Sugestão: “... cinco anos antes do procedimento, o paciente começou a apresentar....”).

Deve-se evitar qualificar os procedimentos ou exames com adjetivos como: "minucioso", "cuidadoso", "exaustivo", pois o leitor acredita que deva ser sempre desta maneira ${ }^{7}$. Os laudos de exames, procedimentos e necropsia não devem ser transcritos na íntegra, mas apenas conter as informações mais importantes à interpretação do caso. Exames clínicos ou laboratoriais negativos só devem ser incluídos quando absolutamente necessários à compreensão do caso ${ }^{2,7}$. Devem constar as medicações com nome comercial, nome do laboratório, dosagem e período desde a última dose tomada. Os possíveis efeitos adversos e interações das mesmas também devem ser reportados. Em se tratando de técnica cirúrgica, esta deve ser descrita com pormenores suficientes para poder ser reproduzida pelo leitor.

A discussão deve enfatizar a prioridade e singularidade do relato, a acurácia do diagnóstico e a sua validade em comparação com os dados da literatura, e os subsídios para se levantar novas perspectivas, aplicações ou conhecimentos com o mesmo. O autor deve descrever sucintamente os dados da literatura, comparando e avaliando contrastes e nuances com o caso relatado. Havendo muitos artigos, estes podem ser resumidos em tabelas comparativas para facilitar o entendimento (os detalhes de cada artigo devem, na verdade, ser objeto de outro tipo de publicação, como os artigos de revisão ${ }^{2}$ ). Todos os artigos citados no artigo devem estar nas mãos dos autores na íntegra, para evitar que sejam reproduzidos erros ou omissões de outros autores.

Finalmente, deve-se resumir os principais aspectos do seu caso, justificar a sua singularidade ou raridade, sugerir recomendações e apontar as conclusões. Nas conclusões, o autor deve ser cuidadoso, uma vez que se trata de um ou poucos casos relatados, sem poder estatístico para estabelecer uma evidência científica forte ${ }^{1}$.

Os relatos de caso constituem assim uma forma de apresentação científica bastante simples e importante para figurar nas revistas médicas. O J Vasc Bras está aberto a este tipo de publicação e o Conselho Editorial costuma avaliar com cuidado e atenção este tipo de contribuição dos autores. Reiteramos o convite feito aos colegas da SBACV e convidamos os colegas das demais Sociedades Vasculares, principalmente latinoamericanas, a enviarem seus trabalhos para esta nossa revista.

\section{Referências}

1. El Dib RP. Como praticar a medicina baseada em evidências. J Vasc Bras. 2007;6:1-4.

2. Cohen H. How to write a patient case report. Am J Health Syst Pharm. 2006;63:1888-92.

3. Gottlieb GJ, Ragaz A, Vogel JV, et al. A preliminary communication on extensively disseminated Kaposi's sarcoma in a young homosexual men. Am J Dermatopathol. 1981;3:111-4.

4. Volodos' NL, Shekhanin VE, Karpovich IP, Troian VI, Gur'ev IuA. [A self-fixing synthetic blood vessel endoprosthesis]. Vestn Khir Im II Grek. 1986;137:123-5.

5. Galego GN, Silveira PG. Endopróteses revestidas. In: Maffei FHA, Lastória S, Yoshida WB, Rollo HA, organizadores. Doenças vasculares periféricas. $3^{\mathrm{a}}$ ed. Rio de Janeiro: Medsi; 2002. p. 891-8.

6. Yoshida WB. A redação científica. J Vasc Bras. 2006;5:245-6.

7. Sauaia N, Sauaia MA. Redação do trabalho científico. VApresentação de caso. Arq Bras Cardiol. 1983;40:229-31. 